\title{
Análise da matriz energética e econômica das culturas de arroz, soja e trigo em sistemas de produção tecnificados no Rio Grande do Sul
}

\author{
Matrix analysis of energy and economic crop of rice, soy and wheat in intensive production \\ system in Rio Grande do Sul, Brazil
}

\author{
Fernanda de Figueiredo Ferreira ${ }^{\mathrm{I}}$ Pedro Selvino Neumann ${ }^{\mathrm{II}}$ Ronaldo Hoffmann ${ }^{\mathrm{III}}$
}

RESUMO

A presente análise tem a finalidade de comparar o desempenho entre unidades e atividades produtivas, interligando os parâmetros energéticos aos econômicos. O objetivo deste trabalho foi analisar a relação entre a energia produzida $e$ consumida durante o processo de produção das principais culturas de cereais do Estado do Rio Grande do Sul, a saber trigo, arroz e soja, em contraposição aos resultados econômicos das respectivas atividades. A pesquisa foi do tipo exploratória, a partir de estudos de multicaso, com uso de pesquisa bibliográfica, análises de laboratório e entrevistas. Para determinar os resultados de análises energéticas, foram realizados os balanços energéticos e as eficiências culturais e energéticas das culturas. Para determinar os resultados econômicos das atividades estudadas, foi utilizada a Teoria do Valor Agregado. Os resultados demonstram que a atividade da soja, em sistema de plantio direto com rotação de culturas, alcançou a maior eficiência energética, entre 25,58MJ ha- a 38,39MJ ha ${ }^{-1}$, sendo que a relação de menor eficiência foi a cultura do trigo, com 3,13MJ ha-1. Em relação ao desempenho econômico das culturas, a soja igualmente mostrou a melhor eficiência econômica igual a 2,47 e a do trigo foi de 1,14 a menor. Cabe destacar os significativos resultados econômicos obtidos pela cultura do arroz, expressos pelo alto valor agregado, obtido por unidade de área (VAL/ha de $R \$ 3.802,00)$ em função de sua alta produtividade física. Apesar dos indicadores energéticos serem positivos, houve significativos gastos com fertilizantes, combustíveis e agrotóxicos em todas as propriedades estudadas. Dessa forma, reforça-se a importância do debate sobre a sustentabilidade socioambiental dos sistemas estudados, principalmente quando analisados sob a ótica dos gastos energéticos de bens não-renováveis e da problemática social atribuída à mão-de-obra.

Palavras-chave: eficiência energética, eficiência econômica, eficiência cultural, balanço energético, custo de produção, sistemas de cultivo da soja, arroz e trigo.

\section{ABSTRACT}

The energy analysis aims to compare the performance between productive units and activities, searching an approach to link the energy with the economic. Objectives is the analysis of the energy produced and consumed during the production process of major crops in the state of Rio Grande do Sul, namely, rice, soybeans and wheat, opposed to the economic results of such activities. The research was exploratory and based on multicase studies with the use of literature review, laboratory analysis and interviews. To determine the results of energy analyzes were performed energy audits and energy efficiencies and cultural crops, while for the economic results we used the theory of Earned Value. The results demonstrate that the activity of soybean in no-tillage system with crop rotation achieved the highest energy efficiency between 25.58MJ ha-1 and 38.39MJ ha-1, whereas wheat culture showed the lowest efficiency with 3.13MJ ha-1. Regarding the economic performance of crops, soybeans showed the highest economic efficiency 2.47 and wheat the lowest 1.14. It is worth mentioning the significant economic results achieved by the rice crop, expressed by the high added-value obtained per unit area (VAL/ha $R \$ 3,802.00)$ due to its high physical productivity. In spite of having positive energy indicators, significant expenses on fertilizer, fuel and pesticides were observed in all properties studied. Thus, we reinforce the importance of the debate on social and environmental sustainability of the systems studied, especially when analyzed from the perspective of energy expenses of nonrenewable resources and social problems attributed to workforce.

Key words: energy balance, energy efficiency, economic efficiency, cost of production, cropping system of soybean, rice and wheat.

\section{INTRODUÇÃO}

Os cenários agrícolas contemporâneos têm mostrado a alta demanda por energia para

INúcleo de Estudos em Agricultura Familiar (NESAF), Universidade Federal de Santa Maria (UFSM), 97105-900, Santa Maria, RS, Brasil. E-mail: fefiferreira@gmail.com. Autor para correspondência.

"Departamento de Educação Agrícola e Extensão Rural (DEAER), UFSM, Santa Maria, RS, Brasil.

IIIDepartamento de Engenharia Química, UFSM, Santa Maria, RS, Brasil. 
incrementar e viabilizar os processos produtivos da agropecuária, além de suas interfaces econômicas e ambientais que encadeiam a ênfase na qualidade e produtividade nos diferentes sistemas de produção. Nesse conflito, entre a busca da sustentabilidade e de novos padrões de consumo, no que tange à produção em longo prazo, verifica-se a necessidade de entender os fluxos de energia e dos ciclos de matéria, elementos estruturais da produtividade ambiental (FERREIRA, 2010). Deste modo, as análises energéticas devem revestir-se, portanto, de igual importância para o planejamento da atividade agrícola, juntamente com a análise econômica, sendo talvez aquela que traduza de forma privilegiada as principais conjunturas de sustentabilidade das unidades de produção (FERREIRA \& NEUMANN, 2011).

A análise ecológico-energética objetiva a comparação do desempenho energético entre unidades produtivas e procura uma abordagem no sentido de interligar os parâmetros energéticos aos econômicos, sociais e culturais, na gestão dos recursos naturais dos sistemas socioeconômicos. Um sistema tecnologicamente adequado, que busca maior eficiência na utilização da energia não-renovável e no lucro, somente poderá ser estabelecido mediante uma racionalização das atividades executadas na propriedade (IGUE, 1980).

Os estudos realizados até hoje geralmente comentam a necessidade do desenvolvimento das pesquisas com balanços energéticos, no sentido de buscar meios para que estes tenham maior relação com a região, diferindo de aspectos globais e da agricultura proposta por outros países, com características bem diferentes do Brasil.

Para BUENO (2002), as análises de fluxos energéticos se dão em nível de ecossistemas, isto é, enfoques de avaliação da estabilidade de agroecossistemas pelas entradas de energia, associadas às suas saídas em forma de calor e biomassa produzida. O autor apoiou seus estudos na classificação de fluxos energéticos adotados por COMITRE (1993), na qual as formas de entrada de energia no agroecossistema, como mão-de-obra, sementes e trabalho animal, são consideradas de origem biológica; óleo diesel, lubrificantes e graxas são de origem fóssil; e ambas (biológica e fóssil) são consideradas energia do tipo direta. Máquinas, implementos, corretivo de solo, adubos químicos e agrotóxicos foram considerados formas de energia de origem industrial do tipo indireta. Nesse sentido, uma análise dos fluxos de energia em qualquer sistema requer medir o uso da energia.

\section{MATERIAL E MÉTODOS}

A pesquisa foi do tipo exploratória e seguiu as orientações metodológicas que contemplam estudos de casos múltiplos, com uso de pesquisa bibliográfica, análises de laboratório e entrevistas com os produtores. Nesses estudos de casos múltiplos, as unidades de produção escolhidas são diferenciadas pelos sistemas de produção adotados, o que concebe a não generalização de seus resultados, mas como suporte e ferramenta para outros estudos, já que não são considerados “unidades de amostragem”.

Dessa forma, foram escolhidas três UPAs com as seguintes características: UPA A: Cultivo de arroz irrigado, através do sistema mix, adotado pelo IRGA (Instituto Riograndense de Arroz), juntamente com o sistema de integração lavoura-pecuária. Ainda cultiva soja, no sistema de plantio direto, e azevém. UPA B: Cultivo de arroz irrigado, através do sistema mix, adotado pelo IRGA, bem como sistema de integração lavoura-pecuária. Ainda cultiva soja, no sistema de plantio direto, e azevém. UPA C: Cultivo de trigo no inverno, sistema de plantio direto, além da cultura de soja, sistema de plantio direto.

As coletas de dados foram realizadas através de visitas às propriedades, em busca de informações sobre o sistema de produção adotado, a dinâmica da propriedade, bem como a coleta dos dados amostrais que expressam as variáveis $\mathrm{C}$ e $\mathrm{N}$, que participam do processo de produção. As visitas, entrevistas e coleta de dados culturais foram realizadas no período de novembro de 2007 a maio de 2009. Os cálculos foram realizados considerando o consumo energético com mão-de-obra, sementes, fertilizantes e agrotóxicos (herbicidas, inseticidas, fungicidas), máquinas e equipamentos, além dos combustíveis (óleos lubrificantes, graxas e óleo diesel). As equações para a base de cálculos teve como referência os trabalhos desenvolvidos por SERRÃO \& OCÁCIA, (2006). Para a determinação dos resultados econômicos das atividades estudadas, foi utilizada a teoria do Valor Agregado (DEFUMIER, 1996; LIMA et al., 2001). O valor agregado é uma medida que procura distinguir a geração de bens e serviços da sua distribuição entre os diferentes agentes que participam da produção.

\section{RESULTADOS E DISCUSSÃO}

A quantificação e a qualificação das unidades de produção foram realizadas a partir da reconstituição do itinerário técnico, referente a cada sistema de produção, compondo tanto os fluxos de energia quanto as variáveis que compõem os custos econômicos de cada cultura. 
Dispêndios energéticos das culturas estudadas

$\mathrm{Na}$ construção da matriz energética das culturas de trigo, arroz e soja, iniciou-se pela definição do agroecossistema, caracterizando-se pelo período enfocado, detalhando-se, em seguida, o itinerário técnico percorrido e elaborando, a seguir, as entradas operacionais. Os itens que compõem a matriz de exigência física da cultura foram transformados em coeficientes energéticos, conforme especifica a metodologia. O sistema foi delimitado de forma a englobar as atividades relativas à dessecação, semeadura e colheita da soja e do trigo, incluindo todos os processos produtivos, gastos energéticos embutidos nas respectivas atividades, ao passo que, para a cultura do arroz irrigado, acrescenta-se a sistematização e organização das áreas de produção.

Dessa forma, as variáveis que orientam as discussões sobre a matriz energética das respectivas culturas, referentes aos dois anos agrícolas, estão dispostas na tabela 1. Entre os componentes responsáveis pelos maiores gastos energéticos, destacam-se os fertilizantes e os combustíveis, responsáveis por mais de $70 \%$ do consumo de energia, na cultura do trigo.

Os fertilizantes, identificados pela energia indireta e de ordem industrial que entram no sistema de produção, como nitrogênio, fósforo, potássio e calcário, respondem por 38,90\% do consumo energético total. Destaca-se o alto consumo de nitrogênio (N), utilizado tanto nas aplicações de base como de cobertura, respondendo por 79,62\% da energia aportada pelos fertilizantes. Já os combustíveis totalizam 33,64\% do consumo energético total, divididos entre óleo diesel, lubrificantes e graxas. Os agrotóxicos têm uma expressão de 5,48\%, da energia aportada na cultura do trigo, sendo que, destes, 49,85\% referem-se ao uso de herbicidas, forma mais utilizada para dessecação, no sistema de plantio direto. Este sistema permite o controle de plantas invasoras com diferentes princípios ativos e mantém a cobertura do solo. Perde-se, entretanto, na seleção de inimigos naturais e no desequilíbrio do agroecossistema, que se torna cada vez mais dependente de "novas moléculas” para manter o equilíbrio de pragas e ervas invasoras.

O gasto energético com sementes foi responsável pelo consumo de 20,05\% das entradas, embora o poder calorífico de 13,83MJ ha-1 ${ }^{-1}$ encontrado no grão, seja relativamente pequeno, em comparação a outras culturas. Dessa forma, a produtividade do trigo foi de $2.580 \mathrm{~kg} \mathrm{ha}^{-1}$, bem superior à média do RS que fica entorno de $1.984 \mathrm{~kg} \mathrm{ha}^{-1}$. Nesse sentido, o valor energético encontrado no grão, além da elevada contribuição na alimentação humana, serve de base alimentar para animais, através do complemento encontrado pelas concentrações de carboidratos, gorduras e proteínas que compõem a massa do grão, podendo ser estimado pela energia bruta.

Em relação à cultura do arroz irrigado, ressalta-se a significativa contribuição dos fertilizantes, para ambas as UPAs que compõem este estudo. Na UPA A, o gasto energético com fertilizantes equivale a 36,92\% (na média), para as duas safras estudadas. Já para a UPA B, a participação foi de 53,66\% em 2007 e de $51,85 \%$ no ano de 2008 . Na ordem de contribuição dos gastos energéticos, os combustíveis participam com um percentual de 28,50\% dos gastos totais para a UPA A e $23,71 \%$ para a UPA B. Essa diferença pode estar condicionada ao processo de irrigação adotado, pois, na UPA B, a rede de energia elétrica contempla grande parte das lavouras.

Merece menção a participação atribuída a fertilizantes, combustíveis e agrotóxicos que, somados, atingem um percentual de $71,69 \%$ do total dos gastos energéticos na UPA A e $81,64 \%$ na UPA B. Dessa forma, ganham importância as políticas que norteiam os indicadores ou limites de "contaminação" refletidas pelo Código das Águas.

Tabela 1 - Média dos dispêndios energéticos, por hectare, das culturas de trigo, arroz e soja, safras 2007 e 2008.

\begin{tabular}{|c|c|c|c|c|c|c|}
\hline Variáveis & Energia & $\%$ & Energia & $\%$ & Energia & $\%$ \\
\hline Agrotóxicos & 624,17 & 5,48 & $1.044,55$ & 6,11 & $1.686,64$ & 22,28 \\
\hline Combustíveis & $3.828,25$ & 33,64 & $4.841,19$ & 28,31 & $3.350,88$ & 44,26 \\
\hline Fertilizantes & $4.427,14$ & 38,90 & $6.960,54$ & 40,71 & 212,81 & 2,81 \\
\hline Mão de obra & 7,93 & 0,07 & 13,42 & 0,08 & 9,15 & 0,12 \\
\hline Máquinas e equipamentos & 211,44 & 1,86 & 938,69 & 5,49 & 471,86 & 6,23 \\
\hline Sementes & $2.281,95$ & 20,05 & $3.299,48$ & 19,30 & $1.839,20$ & 24,29 \\
\hline Total & $11.380,88$ & 100,00 & $17.097,87$ & 100,00 & $7.570,54$ & 100,00 \\
\hline
\end{tabular}

Fonte: Síntese dos dados de campo, referentes às safras 2007 e 2008. 
Em manejo similar, as duas UPAs trabalham com a integração lavoura-pecuária. A primeira, ao longo dos dez anos de plantio direto, desenvolve esta atividade casada com a lavoura e sistema de pousio alternado, com pastagens de azevém em conjunto com a carga animal. Estudos de ALVARENGA et al. (2007) apontam para os benefícios que esse sistema proporciona ao solo, respeitando a carga animal, a oferta de forragem e a reciclagem de nutrientes.

Os resultados contemplados na tabela 1 , em relação aos gastos energéticos da cultura da soja, referentes aos dois anos agrícolas, na UPA A, mostraram que os valores energéticos empregados para o desenvolvimento da cultura foram os mesmos, repetindo-se também a quantidade de área para o cultivo. $\mathrm{O}$ aporte energético investido em energia direta, como óleo diesel, lubrificante e graxa, na área de estudo, corroboram as estimativas apresentadas por BONNY (1993), que relaciona diretamente ao consumido no sistema agrícola, quando este se refere ao uso intensivo.

Entretanto, a relação entre combustíveis e agrotóxicos permanece na mesma linha de importância, dada a composição da matriz energética do agroecossistema soja, para as três UPAs estudadas. Dessa forma, o dispêndio energético empregado em combustíveis na UPA B é de 39,71\%, já, para a UPA C, a média para ambos os anos foi de $44,78 \%$; participação semelhante foi encontrada em trabalhos realizados por QUESADA et al. (1987), com valor de 46,5\% para essa cultura, no Rio Grande do Sul. Em menores proporções, para a cultura da soja, máquinas e equipamentos correspondem a 3,66\% da média do total de energia, à UPA C, 5,62\% à UPA A e 8,49\% à UPA B. A menor participação foi para a UPA C que, neste caso, exprime a melhor relação quantidade de hectares por hora máquina manejados. Assim, na questão energética, demonstra-se a eficiência empregada nas máquinas e equipamentos, tendo uma boa diluição no restante das atividades realizadas na UPA.

A participação das energias diretas e de fontes biológicas, verificada nas sementes na UPA C, apresenta tendência semelhante aos trabalhos de BUENO (2002), que contempla 31\% do total de energia consumida no sistema; já para a variável mão-de-obra, essa proporção é de $0,15 \%$, fazendo uma correlação direta entre a agricultura altamente mecanizada com problemas de cunho social, enfrentados pela menor oferta de emprego no campo.

Análise do balanço energético e econômico das culturas estudadas

Para análise do balanço energético, foram utilizados os resultados encontrados pelas "entradas" e "saídas" de energia de cada cultura, relacionandoas com os índices energéticos dos respectivos grãos. Dessa forma, a análise quantificada pelos dispêndios energéticos de cada matriz de produção exprime os valores de produtividade, a energia produzida em grãos por unidade de área, a energia consumida por hectare, bem como a relação entre a eficiência energética e a eficiência cultural.

Ao passo que o desempenho econômico é composto das seguintes variáveis: produto bruto (PB), consumo intermediário (CI), valor agregado bruto (VAB), valor agregado líquido (VAL), depreciação (D), distribuição do valor agregado (DVA) e renda agrícola (RA). Esses itens identificam os cálculos de viabilidade econômica das culturas que compõem este estudo. Os indicadores dispostos na tabela 2 constituem-se de elementos importantes para a melhor compreensão das dinâmicas empregadas pelo produtor, através de parâmetros como valor agregado (VA), que identifica as riquezas advindas da unidade de produção agrícola, bem como as interações de eficiência técnica e econômica por meios distintos, que contemplam o processo de produção.

Dessa forma, o presente estudo procura fazer uma análise de suas correlações, no intuito de identificar uma abordagem metodológica mais consistente, interligando as decisões de cunho energético e econômico, observando a amplitude social e ambiental dos agroecossistemas descritos. Assim, em relação aos gastos energéticos, a energia consumida por hectare na cultura do trigo, na UPA C, conforme referências proporcionais à área de produção de 54ha, correspondem a 11.380,08MJ ha-1, com um crédito efetivo de $24.300,52 \mathrm{MJ} \mathrm{ha}^{-1}$, ou seja, saldo energético positivo. Outro fator que chama a atenção em estudos mais recentes é o aumento da eficiência energética e produtividade cultural do sistema trigo associado a outras culturas.

Em estudos com cevada e trigo, desenvolvidos por SANTOS et al. (2001), em plantio direto, determinaram-se índices de produtividade cultural de trigo entre 1,20 a $1,24 \mathrm{Mcal} \mathrm{ha}^{-1}$. Valores mais altos de conversão foram encontrados pelos autores QUESADA et al. (1987), os quais obtiveram os seguintes valores para trigo: 1,89 e 316.014Mcal ha-1. Em pesquisas comparativas entre sistema convencional e orgânico, desenvolvido em área experimental, por PIMENTEL et al. (1983), observaram-se as culturas de milho, trigo, maçã e batata, sendo que o trigo e o milho apresentaram melhor eficiência energética em sistema orgânico.

Em diferentes proporções, o resultado do $\mathrm{VAB}$ ha $^{-1}$ encontrado para o trigo é bastante baixo, 
Tabela 2 - Comparação entre os indicadores que compõem a análise dos resultados energéticos e econômicos das culturas de trigo, arroz e soja, safras 2007 e 2008.

\begin{tabular}{llll}
\hline Variáveis/Valores médios & Trigo & Arroz & Soja \\
\hline Energia produzida ha $^{-1}$ (energética) & $35.681,40$ & $206.027,56$ & $102.393,28$ \\
Produto bruto ha $^{-1}$ (econômica) & $1.008,00$ & $4.456,00$ & $1.750,39$ \\
Energia consumida ha $^{-1}$ (energética) & $11.380,89$ & $17.097,87$ & $7.570,54$ \\
Custo total ha $^{-1}$ (econômica) & 882,13 & $3.438,15$ & 709,36 \\
Balanço energético ha $^{-1}$ & $24.300,52$ & $188.929,70$ & $94.822,74$ \\
Valor Agregado Líquido ha $^{-1}$ & 125,87 & $2.501,50$ & $1.041,02$ \\
Eficiência cultural & 3,14 & 12,12 & 13,66 \\
Eficiência energética & 9,32 & 42,62 & 30,81 \\
Eficiência econômica & 1,14 & 2,28 & 2,47 \\
\hline
\end{tabular}

Fonte: Síntese dos dados de campo, referentes às safras 2007 e 2008.

de $\mathrm{R} \$ 193,10 \mathrm{ha}^{-1}$, principalmente, se comparado com o desempenho das outras culturas. Em relação à análise econômica da cultura do trigo, cabe destacar que, mesmo o (VAL ha-1) sendo considerado baixo, de $\mathrm{R} \$ 125,87$, ele ainda é positivo, demonstrando que existe agregação de valor à sociedade. É importante destacar que a eficiência cultural encontrada foi de 3,13, indicando uma agregação energética de $213 \%$, enquanto que a eficiência econômica foi de 1,14 , o que representa $14 \%$ de agregação em termos de valor monetário. No aspecto de eficiência energética, a cultura do trigo obteve o equivalente a 9,35, demonstrando a quantidade de energia fóssil demandada pela cultura, ainda que, a cada unidade de energia fóssil utilizada, o retorno seja de 8,35 unidades de energia na produção de trigo.

$\mathrm{Na}$ cultura do arroz, utiliza-se de duas informações importantes para a produção de energia: a primeira atenta para a estimativa do potencial de uso da palhada, quantificada pelos retornos benéficos ao sistema produtivo e pelas condições de sustentabilidade ambiental. A segunda, de cunho mais produtivista e social, à medida que salientam o resultado energético produzido no grão, dando ênfase às questões de soberania alimentar, através da quantificação calórica. A ênfase dada a essa variável (palhada), remete-se aos possíveis potenciais de sustentabilidade, observados e discutidos pelo Protocolo de Kyoto, através da quantificação da queima de carbono, bem como no potencial de produção energética adotado em países da Europa Ocidental. Os dados encontrados remetem ao trabalho de campo, que, de maneira geral, expressa a média de matéria-seca ofertada em gramas por metro linear. Nessa condição de campo, a quantidade média encontrada de matéria-seca, nos dois anos agrícolas, para a UPA B foi de 472,85g $\mathrm{m}^{-1}$.
O grão de arroz apresenta índice de energia disponível de 30,44 MJ ha-1, em função da alta produtividade por hectare, que corresponde a 211,66 sacos ha-1 ${ }^{-1}$ além de apresentar um elevado (PB). O (VAB ha $^{-1}$ ) é de R\$ 2.800,05, demonstrando a boa eficácia técnica alcançada pela propriedade. O (VAL), que é de $\mathrm{R} \$ 3.802,28$ para cada unidade de área, representa um valor alto, sendo um bom indicador da eficiência econômica. A análise energética e econômica restringese a UPA B, em menção a apenas esta apresentar o cálculo econômico. Em termos de eficiência econômica, a UPA apresenta um índice de 2,28.

É na cultura do arroz irrigado que se alcançam os maiores valores absolutos, em relação ao balanço energético e também ao valor agregado por unidade de área com a atividade, explícitos em grande parte pela alta energia produzida e o alto produto bruto por unidade de área. Dessa forma, a eficiência energética da UPA B foi de 40,95, com retorno de 39,95, para cada unidade utilizada de energia fóssil. Assim, a eficiência energética agrega 3.995\% na UPA B. Para os indicadores de eficiência energética, foi encontrado o valor de 31,26, indicando que, para cada unidade de energia fóssil empregada no sistema de produção, o retorno energético é de 30,26 . Ao passo que a cultura da soja que apresenta os melhores indicadores de eficiência cultural e de eficiência econômica, sendo eles de 13,66 e 2,47, respectivamente.

\section{CONCLUSÃO}

A energia total consumida, representada pelas "entradas" culturais para o cultivo do trigo, arroz e soja, foi, respectivamente: $11.380,88 \mathrm{MJ} \mathrm{ha}^{-1}$, $17.097,87 \mathrm{MJ} \mathrm{ha}^{-1}$ e $7.570,54 \mathrm{MJ} \mathrm{ha}^{-1}$. Assim, podese observar que a cultura do arroz irrigado apresenta 
maior dispêndio energético, enquanto que a cultura da soja só necessita $44 \%$ desta energia. Chama-se a atenção para as diferenças energéticas empregadas para cada sistema de produção e as consequências a médio e longo prazo pelo acúmulo de insumos, frente às contaminações primárias do solo, do ar e principalmente da água, dadas a magnitude de energia necessária para produção.

As variáveis que mais competem no dispêndio energético total, para a composição desta matriz são os combustíveis seguidos dos fertilizantes, agrotóxicos e sementes. Para as culturas do arroz e do trigo, a variável de maior contribuição foram os fertilizantes, com proporção de $40,71 \%$ e de $38,90 \%$ dos gastos totais do dispêndio energético. Outra variável importante na matriz dos dispêndios energéticos das culturas analisadas foi a significativa participação dos combustíveis fósseis em todas elas. Na soja, representou 44,26\% dos dispêndios totais, já na cultura do trigo foi de $33,64 \%$ e no arroz de $28,31 \%$.

Na dimensão das variáveis que compõem a renda agrícola do trigo, destaca-se a pouca diferença, em termos de valores monetários, entre o produto bruto e consumo intermediário, o que resulta em baixo Valor Agregado Bruto por hectare VAB ha-1 ${ }^{-1}$ de R \$ 193,10. O oposto dessa relação acontece para a cultura do arroz, quando ambos os valores gerados para o PB/ha é de R\$ 4.456,00 também influenciado pela alta produtividade do arroz, que corresponde a 132,25 sacos ha ${ }^{-1}$. Assim, o VAB ha-1 é de R\$2.800,05, demonstrando a boa eficácia técnica alcançada pela propriedade. De maneira intermediária, a cultura da soja apresenta um PB ha ${ }^{-1}$ de R \$ 1.750,39 e um VAB ha-1 de R \$1.158,30. Aqui o CI é baixo de R\$592,09, justificando a boa eficácia técnica encontrada pelo VAB.

Apesar da agregação de valor, medido através do VAL, ser positiva em todas as culturas, a renda agrícola da cultura do trigo resultou em um valor negativo de $\mathrm{R} \$-407,19$ por hectare, diferentemente dos valores encontrados para arroz de R $\$ 1.017,85$ e para a soja de $\mathrm{R} \$ 589,09$.

Menciona-se a boa relação entre as ferramentas metodológicas do balanço energético e as utilizadas pela análise econômica, através da analogia entre os indicadores. O melhor indicador de eficiência cultural e de eficiência econômica foi alcançado pela cultura da soja, (13,66 e 2,47). Já o trigo alcançou os piores indicadores, tanto na eficiência cultural $(3,14)$ como na econômica $(1,14)$. O arroz obteve valores intermediários (12,12 e 2,28), embora tenha alcançado os maiores valores absolutos, tanto energéticos quanto econômicos, em função da grande produtividade por unidade de área. Ao pensar nas projeções futuras, referentes a este estudo, é preciso atentar à necessidade de um olhar mais voltado à complexidade dos agroecossistemas em questão, procurando observar os limites e potencialidades das atividades em conjunto e da análise mais apurada de sua sustentabilidade socioambiental, considerando a ótica dos gastos energéticos de bens não-renováveis e da problemática social atribuída à mão-de-obra.

\section{REFERÊNCIAS}

ALVARENGA, R.C. Sistema de integração lavoura-pecuária: o modelo implantado na Embrapa Milho e Sorgo. Sete Lagoas, MG: EMBRAPA, 2007. (ISSN 1518-4269. Circular Técnica, 93).

BONNY, S. Is agriculture using more and more energy? A French case study. Agricultural Systems, Kidlington, v.43, n.1, p.51-66, 1993.

BUENO, O.C. Análise energética e eficiência cultural do milho em assentamento rural. 2002. 146f. Tese (Doutorado em Energia na Agricultura) - Curso de Pós-graduação em Agronomia, Faculdade de Ciências Agronômicas, Universidade Estadual Paulista, São Paulo, SP.

COMITRE, V. Avaliação energética e aspectos econômicos da filiére soja na região de Ribeirão Preto - SP. 1993. $152 \mathrm{f}$. Dissertação (Mestrado em Engenharia Agrícola/Planejamento Agropecuário) - Faculdade de Engenharia Agrícola, Universidade Estadual de Campinas (UNICAMP), Campinas, SP.

DEFUMIER, M. Projetos de desenvolvimento agrícola: manual para especialistas. Salvador: EDUFBA, 2007. 328 p.

FERREIRA, F. de F. Análise da matriz energética e econômica das culturas de arroz, soja e trigo em sistemas de produção tecnificados no Rio Grande do Sul. 2010. 149f. Dissertação (Mestrado em Engenharia de Produção) - PPGE, Universidade Federal de Santa Maria, RS.

FERREIRA, F. de F.; NEUMANN, P.S. Análise da matriz energética e econômica das culturas da soja e trigo em sistemas de produção tecnificados no Rio Grande do Sul. In: CONGRESSO DE SOCIOLOGIA RURAL, SOBER, 2011, Belo Horizonte, MG. Anais... Belo Horizonte: ed. UFMG, 2011. 1-17 p.

LIMA, A.P. et al. Administração da unidade de produção familiar: modalidades de trabalho com agricultores. 2. ed. Ijuí: UNIJUÍ, 2001. 222p.

PIMENTEL, D. et al. Energy efficiency of farming systems: organic and conventional agriculture. Agriculture, Ecosystems and Enviroment, Amsterdam, n.9, p.359-372, 1983.

QUESADA, G.M. et al. Balanços energéticos agropecuários: uma proposta metodológica para o Rio Grande do Sul. Ciência e Cultura, São Paulo, v.39, n.1, p.20-28, 1987.

SANTOS, H.P. Conversão e balanço energético de sistemas de sucessão e de rotação de culturas. Ciência Rural, Santa Maria, v.31, n.2, p.191-198, 2001. Disponível em: <http://www.scielo.br/ pdf/cr/v31n2/a01v31n2.pdf>. Acesso em: 11 jul. 2008.

SERRÃO, A.A.; OCÁCIA, G.C. Produção de biodiesel de soja no Rio Grande do Sul. Revista Liberato, v.10, n.10, p.3641, 2006. Disponível em: <http://www.liberato.com.br/upload/ arquivos/0102080713361119.pdf>. Acesso em: 08 de maio 2009. 